\title{
Ocular Adnexal Lymphoma cM0 TNM
} Finding v7

National Cancer Institute

\section{Source}

National Cancer Institute. Ocular Adnexal Lymphoma cMO TNM Finding v7. NCI

Thesaurus. Code C88860.

Ocular adnexal lymphoma with no evidence of involvement of other extranodal sites.

(from AJCC 7th Ed.) 